\title{
Time Consistency in Regulatory Price Setting: An Australian Case Study
}

\author{
HENRY ERGAS * \\ Concept Economics
}

\begin{abstract}
Time consistency refers to situations where a policy that is optimal ex ante proves not to be optimal ex post, creating the risk of opportunistic policy reversals. While the threat of such reversals has received widespread attention in the theoretical literature, testing whether policy is indeed time consistent is challenging. This paper implements such a test by comparing the depreciation profile established by the Australian telecommunications regulator at the outset of a regulatory period with the actual path of allowed recovery, and finds that the regulator acted in a time-inconsistent manner.
\end{abstract}

\section{Introduction}

Time consistency is widely recognised as a major issue in public policy, with implications for the design of monetary policy institutions (see for example, Calvo (1978) and Rogoff (1985)), of industry regulation (Evans, Levine and Trillas, 2008) and of environmental policy (Laffont and Tirole, 1996). However, assessing whether policy is indeed time consistent is a challenging task, and the applied literature in this area is very sparse. This paper presents such an assessment for Australian telecommunications regulation.

It can be assumed that readers will be familiar with the concept of time consistency, which simply put, refers to situations where a policy that is optimal (from the point of view of the policy maker) ex ante turns out not to be the optimal policy ex post. If the policymaker cannot commit to a policy, it may then find itself wanting to change its policy ex post (say, after a regulated firm has made an irreversible investment decision), regardless of what it promised ex ante. Such an approach to policy is said to be timeinconsistent - see Kyland and Prescott (1977).

In telecommunications regulation, the issue arises because network investments are largely sunk. It is plausible to suppose that a regulator has an interest in ensuring that efficient network investments are undertaken; clearly, where investment is voluntary, that will only occur if investors expect full capital recovery to occur, at least on an actuarial

\footnotetext{
* Mailing Address: Concept Economics, Level 1, 27 Jardine Street, Kingston ACT 2604. Australia. HenryErgas@concepteconomics.com.au I am especially grateful to Alexis Hardin for her help in the calculations set out below and to Sabine Schnittger. I am also grateful to an anonymous referee for several extremely helpful comments. This work originates in consultancies undertaken for Telstra. However, the opinions expressed are my own, as is responsibility for any errors.
} 
basis. As a result, the optimal policy ex ante is to offer full cost recovery for such investments, though incentive regulation schemes may result in costs being under- or overrecovered ex post. However, once the sunk investment is made, reneging on that promise may be optimal: for a short-run welfare-maximising regulator, if it allows prices to be reduced to marginal costs; or for a regulator that is maximising its popularity, if gains to consumers are weighted more heavily than losses to investors. Obviously, the extent to which such an approach can be sustained in the long run depends on the degree to which the regulated firm can withhold subsequent investment and on the costs of that withholding relative to the gains from forcing prices on existing assets to or towards marginal costs. The factors that affect the sustainability of such a policy of 'regulatory expropriation' are discussed in Levine, Stern and Trillas (2005).

Aspects of Australia's experience with access regulation in telecommunications present an opportunity in which to assess whether regulators act time consistently. This is because the Australian telecommunications regulator has adopted an approach to depreciation that heavily "backloads" cost recovery. By reconstructing the path of promised cost recovery, and comparing it to the actual level of cost recovery allowed, one can test for timeconsistency.

I start by setting out the relevant context and then explain the specifics of the depreciation approach the regulator has adopted, before drawing some lessons and conclusions.

\section{The background}

Since July 1997, a range of telecommunications services have been regulated - in the terms of the relevant statute, 'declared' - under a regime that vests substantial discretion over access charges in the regulator, the Australian Competition and Consumer Commission (ACCC). (The details of the regime and its working are explained in Ergas (2008)). So as to set charges for these services, the ACCC has relied on a forward looking cost standard, which it refers to as Total Service Long Run Incremental Cost (TSLRIC) (see ACCC (1997)), even though, in reality, the models that have been used are versions of the Total Element Long Run Incremental Cost (TELRIC) methodology (see Ergas (1998)).

The relevant thought experiment is that of determining charges "as if" the network were being built through a Chadwick-Demsetz auction under competitive conditions. The expectation of the revenue requirement in such an auction is presumably lower bounded by the TSLRIC estimate, and it is that amount that must be promised if the participation constraint is to be met. ${ }^{1}$

The capital costs determined in a TSLRIC model are essentially a lump of costs, and those costs need to be spread over time. As a general matter, the costs associated with each year will vary - that is, the values associated with year 1 will not be same as those in year 2, which themselves will differ from those in year 3 (and so on). As a result, the choice of which year is taken as a base can matter - that is, the revenue ceiling arising from the

\footnotetext{
${ }^{1}$ Whether that thought experiment has desirable normative implications is an important question - explored in Ergas (2008) - but beyond the scope of this article.
} 
estimate will be different depending on whether it is assumed that we are in year 1 (the network has just been built) or in year 10 (the network is now 10 years old). ${ }^{2}$

This issue can be avoided if instead of calculating the capital charge for a particular year, the capital charge is levelized, that is, is set such that its value is equal in each year of the asset's life. Adopting this approach, the annual capital charge would be calculated as:

$$
C_{l}=\frac{r}{1-(1+r)^{-n}} \cdot \sum_{t=1}^{n} \frac{\left(\bar{w}_{t} \times r+d_{t}\right)}{(1+r)^{t}}
$$

where

$C l$ is the levelized capital charge;

$r$ is the WACC;

$n$ is the useful life of the asset;

$w$ is the written down value of the asset;

and $d$ is depreciation.

Matters are more complicated in the Australian telecommunications regime, however, because access charges need to be set whenever an access dispute occurs and that dispute is referred to the regulator, who has powers of compulsory arbitration. The ACCC's approach has generally been to update the cost estimate at each arbitration. As a result, the expected revenue stream to the access provider is determined by the present value of the sequence of redeterminations.

Viewed from the perspective of an assumed base period, the issue this raises is that of respecting the participation constraint, which as noted, is that (ignoring taxes) the expected value of the stream of quasi-rents be equal to the initial hypothesised investment. Given that the actual amount is periodically redetermined, for the participation constraint to be met, the path of capital recovery promised at the outset must reflect the anticipated redeterminations.

Were input costs constant, or were the current input costs the best estimate of future input costs, this could be achieved through a simple annuity approach to depreciation. However, a simple annuity can be problematic when the best estimate of future input cost changes is not zero. For example, if future input costs are expected to rise in relative price terms, then future levels of the TSLRIC estimate will be higher than the estimate of TSLRIC in the base period. The expected value of future quasi-rents given by successive re-determinations will then exceed the investment outlay required in the base period.

One way of dealing with this is to use a tilted annuity, where the tilt reflects expected relative price changes. In the tilted annuity formulation, the annuity is "shaped" so that anticipated rises in the cost of the asset act to defer the depreciation charge to the future (that is, to back-load the depreciation profile compared to the simple annuity), while

\footnotetext{
2 This is denied in the ACCC (2007b, p.84 at paragraph 420) but the ACCC's claim involves an un-stated, and plainly erroneous, assumption. That assumption is that depreciation only reflects price changes, that is technological obsolescence, which in turn implies there is no wear and tear. This is shown in Ergas (1998).
} 
conversely, anticipated falls in the cost of the asset cause a front-loading of the depreciation charge. A standard formula for such a tilted annuity, $\mathrm{TX}_{\mathrm{t}}$, is given by $\mathrm{TX}_{\mathrm{t}}=$ $(1+\mathrm{g})^{\mathrm{t}-1} \cdot \mathrm{V} \cdot(\mathrm{r}-\mathrm{g}) /\left\{1-((1+\mathrm{g}) /(1+\mathrm{r}))^{\mathrm{N}}\right\} \mathrm{t}=1,2, \ldots \mathrm{N}$, where $\mathrm{V}$ is the cost of the asset, $\mathrm{r}$ is the rate of return, $\mathrm{g}$ is the tilt factor and $\mathrm{N}$ is the asset life. ${ }^{3}$

This is consistent with a result about efficient depreciation in forward looking cost models derived in Mandy (2002) and Mandy and Sharkey (2003). These authors find that when the charges set on the basis of such a model are periodically redetermined, the efficient path of charges depends on the expected path of costs over time. Specifically, if costs are expected to rise (fall) in real terms, then initial charges should be below (above) the levelized (that is, smoothed) charge, assuming that the regulatory commitment to the resulting price path is credible.

The results of relying on a tilted annuity to estimate the capital charge are illustrated in Figure 1, which compares a flat annuity with a tilted annuity, both recovering an initial outlay of $\$ 100$ with a 10 per cent cost of capital, a 30 year asset life and 3 per cent increasing asset price trend. As can be seen from the figure, depreciation under the tilted annuity is negative for the first twelve years, with the bulk of the return of capital occurring in the last five years of the asset's life.

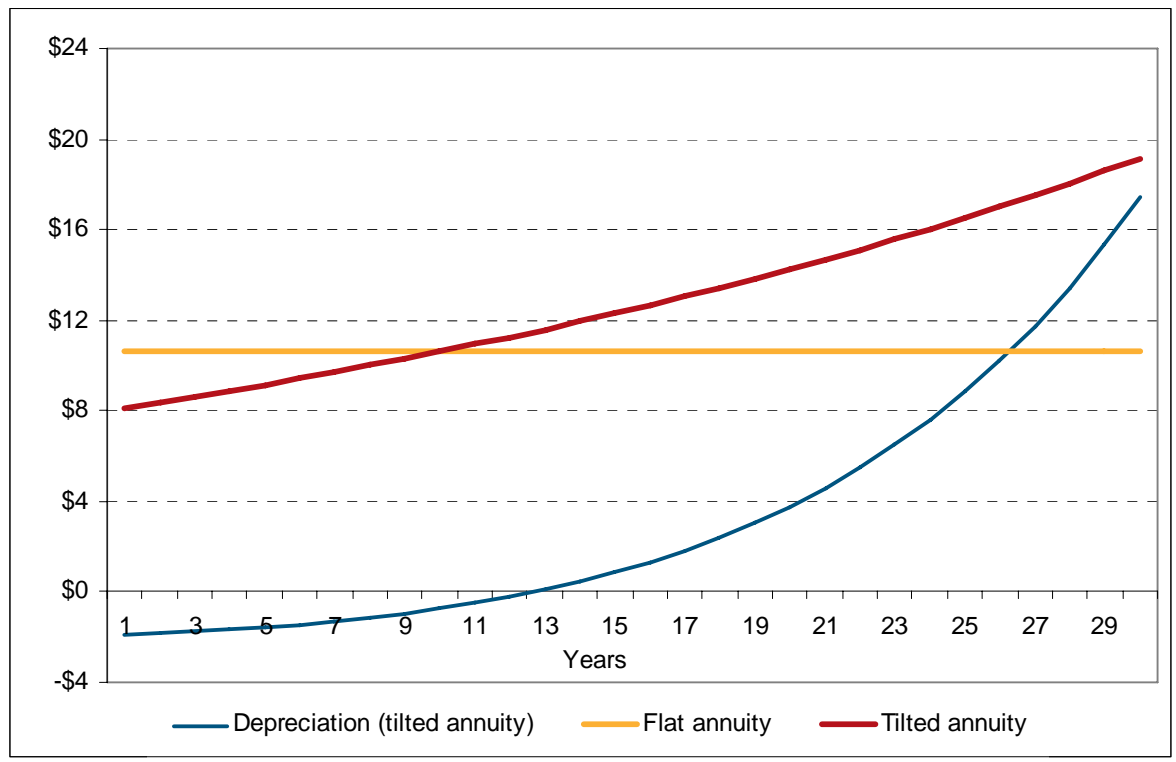

Figure 1: Pattern of cost recovery under a tilted annuity

\footnotetext{
${ }^{3}$ See for example ACCC (2000, p. 102). That said, the ACCC’s formula is incomplete, and likely erroneous, in one important respect. Where the formula will be used in a forward looking cost model to periodically redetermine the relevant charge, the tilt should be corrected to reflect any systematic element in the factors affecting the redetermination (for example, if there is a systematic pattern to the gap between provisioned capacity and capacity determined by the regulator to be efficiently required), and not merely the price term. Failure to do so will impart a systematic bias, leading to either under- or over-recovery in expectation.
} 


\section{The regulator's approach}

The issue of choosing between alternative approaches to determining the depreciation profile first arose in Australian telecommunications regulation in the context of Telstra's proposed access charges for the PSTN for 1997/98. As discussed in Ergas (2008) (on which this section draws), the ACCC, in assessing those charges, commissioned NERA to estimate the TSLRIC of PSTN access.

NERA's view (NERA (1999)) was that the depreciation profile should reflect economic depreciation. ${ }^{4}$ NERA expressly rejected the use of an annuity approach to depreciation, because a constant annualized capital cost (depreciation plus cost of capital) means that depreciation increases each year, that is it is actually back-loaded. While it is possible to tilt the annuity to allow for price and output declines, NERA argued that it requires a large tilt to achieve a declining depreciation profile over time.

Despite NERA's findings, the ACCC, in its Final Report on the Assessment of Telstra's Undertaking (ACCC (1999), p.60), failed to rely on any of the NERA results that used economic depreciation profiles, instead relying solely on the annuity-based results, which were undertaken only as a sensitivity analysis by NERA and only at the suggestion of the ACCC (See NERA (1999), footnotes 48 and 49, p.63).

The ACCC has, since that first assessment, continued to rely on the tilted annuity for estimating the TSLRIC of both PSTN Originating and Terminating Access (OTA) and the Unconditioned Local Loop Service (ULLS). In the case of ULLS, the effect of the tilted annuity formula is to steeply back-load the time profile of cost recovery.

The ACCC's version of the tilted annuity is inconsistent with the profile of economic depreciation, as it fails to take into account other factors that impact on the value of the asset over time, such as wear and tear. ${ }^{5}$ However, even putting the contrast with economic depreciation aside, the central problem is that the price path the ACCC has actually allowed bears little relation to the initial promise of full cost recovery.

This can be seen from Figure 2 , which compares actual ULLS charges (displayed as a charge per ULLS line in nominal dollars on the Y-axis), as initially determined and then successively re-determined by the ACCC, with the charges that would have prevailed had the ACCC respected the time profile of cost recovery as implied by its initial cost modelling. (All estimates are in Australian dollars).

Specifically, the line in Figure 2 above provides an indication of what ULLS prices would have been had a time-consistent tilted annuity been applied to the Commission's initial pricing decision on ULLS; in other words, had the initial tilt been applied to determine prices in subsequent years. The points traced out by that line are the sequence of charges required for the initial "fair bargain" to be paid out. The line slopes up as the ACCC's decision deferred cost recovery to future years.

\footnotetext{
${ }^{4}$ The NERA report defines economic depreciation for any period as the change in the value of the asset during the period. The economic value of an asset at a particular point in time is the present value of expected future revenues derived from the output of the asset less the present value of the operating costs associated with running the asset.

${ }^{5}$ This too was noted by NERA, which emphasized that even where asset prices are not falling over time, declining output and rising operating costs may still require a declining (that is, frontloaded) depreciation schedule - see NERA (1999, p.11). See also the discussion of this point in Ergas (1998). The relevant version of the tilted annuity formula is referenced in footnote 3 above.
} 


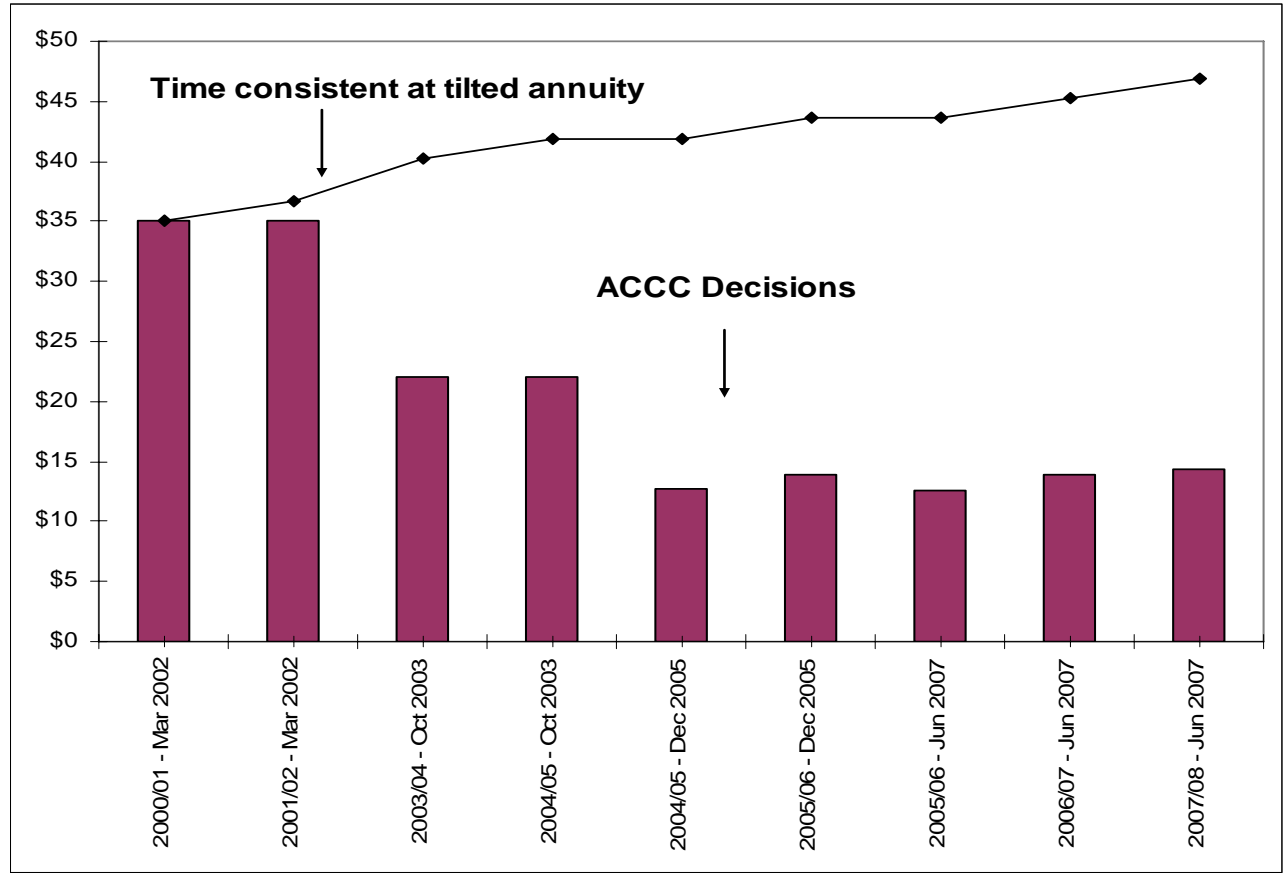

Figure 2: ACCC decisions on monthly band 2 ULLS charges, 2002 to 2007

Sources: Calculated from ACCC (2002), ACCC (2003), ACCC (2005b), ACCC (2007a).

However, what the ACCC has done is not to set prices on the basis of that "fair bargain”. Rather, in part by constantly restarting the clock, the ACCC reduced its estimate of the TSLRIC of ULLS in Band 2 areas from $\$ 35 /$ service/month to just $\$ 13.90 /$ service/month in nominal terms (see bars in Figure 2). In each of these redeterminations, a tilted annuity was applied (albeit with parameters that changed from determination to determination), and the charge was reset based on the first year of the updated annuity. As a result, eventual cost recovery was constantly being deferred.

It is worth noting not only the extent of the overall reduction (and hence of the departure from the pattern of prices implied by the tilted annuity) but also its pattern. In effect, as estimated by the ACCC, costs largely decrease, often sharply, but there are only exceptionally moderate rises. However, if depreciation in a forward looking cost model is set on an actuarially fair basis, the changes in costs at re-estimation should follow a normal distribution (so long as cost shocks are independent), as it should be as likely that the initial estimate of depreciation (which reflects the anticipated change in asset values) will be an under-estimate as it is that it will be an over-estimate. ${ }^{6}$ This contrasts with the pattern of the successive ACCC estimates.

\footnotetext{
6 This will be all the more the case if the discount rate is being determined on the basis of the Capital Asset Pricing Model (CAPM), since (absent quadratic utility functions) the CAPM assumes the cash flows being discounted are the mean of a normal distribution.
} 
Moreover, the pattern of such sharp, successive, declines (albeit with very slight nominal increases towards the period's end) obviously contrasts with the primary justification that can be given for relying on the tilted annuity in the case of the ULLS that it allows predictable, substantial, future rises in relative prices to be taken into account, thus preventing the expected stream of quasi-rents in the base period from exceeding the required base period investment. Were those price expectations indeed reasonable, it would be surprising if out-turns consistently involved large price declines or at best, modest nominal increases.

Those out-turns are even more striking when account is taken of actual cost changes over the relevant period.

Thus, in real (inflation-adjusted) terms, regulated access charges for ULLS declined at an annual rate of 12.7 per cent per annum over the period from April 2002 to September 2007. Even on the ACCC's own estimate, total factor productivity in Telstra's fixed network has been increasing at an annual average rate of 5.4 per cent, and (in trend terms) of less than two per cent. ${ }^{7}$ Moreover, even with that total factor productivity growth, input prices (for important items such as copper and trenching) were rising over that period in nominal terms, as the "China boom" increased world demand for those inputs. ${ }^{8}$ Simulations with Telstra's forward-looking cost model suggest that each one per cent increase in the price of copper-based network elements increases the average cost of ULLS by 0.24 per cent. At the same time, prices for the other key inputs (notably labour and fuel) also increased, in both nominal and real terms. As a result, the expected trend would be for ULLS access charges based on replacement costs to be rising over that period - not decreasing at dramatic rates (since these input price rises have exceeded reasonable estimates of total factor productivity growth). ${ }^{9}$

Underscoring this point is the fact that the ACCC's initial access charges - from which these very large declines have occurred - were derived from estimates of costs for a fully optimised network: that is, for a network that had already achieved all the efficiencies that could be secured. As a result, productivity growth for this "ideal" network would likely be significantly slower than that achievable in the actual network, as some of the productivity growth in the latter will be "catching up" to best practice (that is, to the technological frontier). This makes it even more implausible that the declines mandated by the ACCC have any sensible basis in costs.

\footnotetext{
${ }^{7}$ The ACCC's estimate of 5.4 per cent is heavily influenced by what appears to be a data error in respect of a single year (2000-01). When a trend is fitted, excluding that year, the resulting rate is 1.6 per cent, which is close to the author's own best estimate which is around 2 per cent. The ACCC estimates are in ACCC (2005a).

${ }^{8}$ Prices for electronics have been falling, but electronics accounts for a small share of the cost of a ULLS network. The main cost items in such a network are copper, trenching, maintenance labor and fuel. All of these inputs have had rising relative prices. Moreover, it is worth noting that the increase in copper prices has come to an at least temporary end. Thus Hausman, Sidak and Tardiff (2008) note that copper prices have decreased by some 50 per cent from their peak. There is some evidence that copper prices are mean reverting: see Lederman and Maloney (2006).

${ }^{9}$ A reduction in ULLS specific costs (that is, the incremental costs associated with making the ULLS service available to access seekers) also occurred over the period, but it accounts for a small share of the observed reduction in prices.
} 


\section{Conclusions}

The ACCC's setting of the depreciation profile in regulated access prices provides an opportunity to directly compare the promised path of recovery with the recovery path actually allowed. That comparison shows that the ACCC has ignored the price path implied by its back-loaded depreciation profile, while successively reducing the estimate of the appropriate access charge. These reductions are equivalent to writing off the amount that (through the back-loading of the annuity) had implicitly been deferred to each period from previous periods.

The extent of the resulting cost recovery shortfall is large in absolute terms. It can be quantified in terms of the loss that would be borne by the hypothetical, wholesale-only, access provider, operating a continuously fully optimized network. That amount, taken as the difference between the price path implied by the initial annuity and out-turn charges, compounded from 2002 to the present at an interest rate of 10 per cent, equates to a loss that approaches $\$ 22$ billion.

This is the amount that the hypothetical builder of a new, wholesale only, network the actor in the "thought experiment" underlying TSLRIC - would have lost relative to the initial promise. That loss measures the extent of the time-inconsistency in the pattern of regulatory price-setting. ${ }^{10}$

Since the period covered by Figure 2, the ACCC's approach has remained that of substantially postponing cost recovery. Thus, according to Schnittger (2009), Telstra has calculated the monthly cost of ULLS in metropolitan areas (excluding central business districts) as being in the order of \$48. Taking this amount as a baseline and applying the parameters of the ACCC's most recent tilted annuity (which may differ from those used above, but which have not been publicly disclosed) Schnittger (2009) finds that the allowed monthly charge would be below Telstra's estimated $\$ 47.86$ monthly cost up to and including year 9; but it would exceed Telstra's cost from year 10 onwards, so that the monthly charge would be $\$ 50.77$ in year $10, \$ 77.15$ by Year 20 , and $\$ 187.87$ by Year 40 .

In other words, under the ACCC's approach to depreciation, substantial cost recovery would only occur some fifteen or more years down the track. Moreover, that cost recovery would depend on regulated access charges increasing in real terms over the next two decades, which is in marked contrast to the experience in the decade to date, in which regulated access charges, expressed at constant prices, have declined substantially (see Ergas (2008)). It also seems inconsistent with the prospect of significant advances in wireless technology (which would constrain any such price rises). As a result, the credibility of the regulator's implied commitment to full cost recovery is very low indeed. This is all the more the case given the current regulator's inability, under the statute, to bind future regulatory decisions.

Overall, it is not inconceivable that a backward tilt to cost recovery could be efficient. For example, as noted above, Mandy (2002) and Mandy and Sharkey (2003), in examining the appropriate path of cost recovery, conclude that when periodic price reviews are

\footnotetext{
${ }^{10}$ The quantum of the loss actually borne by a vertically integrated operator would obviously depend on the degree to which any shortfall between the announced path of access charges and actual access charges translated into reductions in retail prices relative to the time consistent counterfactual. Estimates under a range of assumptions as to pass-through can be found in Ergas (2008).
} 
expected, initial prices should be lower than levelized prices when costs are expected to increase over time, and vice versa when they are expected to fall. However, these results assume the regulator's commitment to a given price path is credible.

Moreover, another result in the economic literature on depreciation in economic cost models is also relevant. This result is that uncertainty surrounding future estimates of costs and of demand generally makes it efficient for depreciation to be accelerated, that is for cost recovery to be front loaded, relative to the path determined by a levelized charge. Crew and Kleindorfer (1992) derive this result when the regulated firm is exposed to technological change and competitive entry, while Hausman (2003) and Pindyck (2007) derive it from the need to compensate the firm for making irreversible investments when the return on those investments may be reduced by post-investment "bad news". Obviously, one form of that "bad news" is regulatory opportunism or time-inconsistency, which will generally deter otherwise efficient investment (Guthrie 2006).

In short, even were costs expected to rise over time, the postponement of cost recovery may be harmful in welfare terms unless it can be assumed that regulatory commitments to time-consistent behaviour are credible. The case study set out above casts doubt on the validity of that assumption with respect to the ACCC.

\section{$5 \quad$ References}

Australian Competition and Consumer Commission (ACCC) (2007a) Unconditioned Local Loop Service, Final Pricing Principles.

Australian Competition and Consumer Commission (ACCC) (2007b) Primus/Telstra ULLS, Final Determination, December.

Australian Competition and Consumer Commission (ACCC) (2006) Pricing Principles and Indicative Prices: Local Carriage Service, Wholesale Line Rental and PSTN Originating and Terminating Access Services, Final Determination and Explanatory Statement, 29 November 2006.

Australian Competition and Consumer Commission (ACCC) (2005a) Review of Telstra's Price Control Arrangements: Final report, February.

Australian Competition and Consumer Commission (ACCC) (2005b) Assessment of Telstra's ULLS and LSS Monthly Charge Undertakings, Final Decision, December

Australian Competition and Consumer Commission (ACCC) (2004) Assessment of Telstra's Undertakings for PSTN, ULLS and LCS: Final Decision, December.

Australian Competition and Consumer Commission (ACCC) (2003) Final Determination for Model Price terms and Conditions of the PSTN, ULLS and LCS Services, October.

Australian Competition and Consumer Commission (ACCC) (2002) Pricing of Unconditioned Local Loop Service, Final Report, March. 
Australian Competition and Consumer Commission (ACCC) (2000) A Report on the Assessment of Telstra's Undertaking for Domestic PSTN Originating and Terminating Access Services, July.

Australian Competition and Consumer Commission (ACCC) (1999) Assessment of Telstra's Undertaking for Domestic PSTN Originating and Terminating Access, Final Decision, June.

Australian Competition and Consumer Commission (ACCC) (1997) Access Pricing Principles: Telecommunications - a Guide, 1997.

Calvo, G. (1978) "On the Time Consistency of Optimal Policy in a Monetary Economy,” Econometrica, 46: 1411-28.

Crew, M. A. and P.R. Kleindorfer (1992) "Economic Depreciation and the Regulated Firm under Competition and Technological Change,” Journal of Regulatory Economics, 4:5161.

Ergas, H. (1998) TSLRIC, TELRIC and Other Forms of Forward-looking Cost Models in Telecommunications: A Curmudgeon's Guide.

http://www.greenwhiskers.com.au/papers_reports/papers-ergas-tslric-final-nov98.pdf

Ergas, H. (2008) Wrong Number: Australia's Telecommunications Mess and How to Fix It. Allen \& Unwin: Crows Nest, N.S.W.

Evans, J., P.Levine and F. Trillas (2008) "Lobbies, Delegation and the Under-Investment Problem in Regulation,” International Journal of Industrial Organization, 26: 17-40.

Guthrie, G. (2006) "Regulating Infrastructure: The Impact on Risk and Investment," Journal of Economic Literature, 44: 925-972.

Hausman, J. A. (2003) "Regulated Cost and Prices in Telecommunications," in Gary Madden (ed.), Emerging Telecommunications Networks: The International Handbook of Telecommunications Economics, Edward Elgar Publishing Ltd: Cheltenham, UK ; Northampton, MA.

Hausman, J. A., J. G. Sidak and T. J. Tardiff (2008) “Are Regulators Forward-Looking? The Market Price of Copper Versus the Regulated Price of Mandatory Access to Unbundled Local Loops in Telecommunications Networks," Federal Communications Law Journal, 61: 199-228.

Kyland, F. and E. Prescott (1977) "Rules Rather than Discretion: The Inconsistency of Optimal Plans,” Journal of Political Economy, 85: 473-92.

Laffont, J. and J. Tirole (1996) "Pollution Permits and Environmental Innovation,” Journal of Public Economics, 62: 127-140.

Lederman, D. and W. Maloney (2006) Natural Resources: Neither Curse Nor Destiny. Stanford University Press: Palo Alto, California. 
Levine, P., J. Stern and F. Trillas (2005) "Utility Price Regulation and Time Inconsistency: Comparisons with Monetary Policy,” Oxford Economic Papers, 57: 447-478.

Mandy, David M. (2002) “TELRIC Pricing with Vintage Capital,” Journal of Regulatory Economics, 22: 215-249.

Mandy, D. M. and W.W Sharkey (2003) "Dynamic Pricing and Investment from Static Proxy Models,” Review of Network Economics, 2: 403-439.

NERA (1999) Estimating the Long Run Incremental Cost of PSTN Access, Final Report for ACCC, January.

Pindyck, R. S. (2007) "Mandatory Unbundling and Irreversible Investment in Telecom Networks,” Review of Network Economics, 6: 274-298.

Rogoff, K. (1985) “The Optimal Degree of Commitment to an Intermediate Monetary Target,” The Quarterly Journal of Economics, 100: 1169-1190.

Schnittger, S. (2009) "Tilting the Annuity: the Widening Gap between Theory and Reality,” Communications Day (Australia), Issue of Monday 16 February, 2009. 